\title{
Comparative analysis of drying coffee beans using microwave and conventional oven
}

\author{
Análisis comparativo del secado de granos de café a través de radiación por microondas y \\ radiación térmica \\ Milton Javier Muñoz-Neira (D) ${ }^{1 *}$, Manuel Fernando Roa-Ardila (D) ${ }^{2}$, Carlos Rodrigo Correa-Celi (iD ${ }^{2}$ \\ ${ }_{1}^{1}$ Fundación Universitaria de San Gil, Unisangil. Km. 2 vía San Gíl - Charalá. C. P. 684031. San Gil, Colombia. \\ ${ }^{2}$ Universidad Industrial de Santander, UIS. Cl. 9 \# Cra 27. C. P. 680002. Bucaramanga, Colombia.
}

\section{CITE THIS ARTICLE AS:}

M. J. Muñoz, M. F. Roa and C.

R. Correa. "Comparative

analysis of drying coffee beans

using microwave and

conventional oven", Revista

Facultad de Ingeniería

Universidad de Antioquia, no.

95, pp. 100-108, Apr-Jun 2020.

[Online]. Available: https:

//www.doi.org/10.17533/

udea.redin. 20191151

\section{ARTICLE INFO:}

Received: January 30, 2019 Accepted: November 08, 2019

Available online: November

08, 2019

\section{KEYWORDS:}

Grain drying; drying curve; diffusion coefficient; microwave drying

Secado de grano; curva de secado; coeficiente de difusión; secado por microondas
ABSTRACT: This article reports a comparative study of experimental results obtained during the drying of Castilla-variety coffee beans from Santander, Colombia. They were performed by two means: thermal and electromagnetic radiation. Twenty experiments were carried out, ten tests in a microwave cavity at $2,450 \mathrm{MHz}-1,080 \mathrm{~W}$, and ten tests using a conventional electric oven with temperature controlled at $50 \pm 2^{\circ} \mathrm{C}$. Experiments were made using samples of coffee beans with parchment, without parchment, and of the only-parchment. For each sample, dimensionless moisture ratio and diffusion coefficients were determined, according to the second law of Fick. We found that the diffusion coefficient of the samples dried in a microwave cavity was twenty-two times higher than the diffusion coefficient of samples dried with thermal radiation. Likewise, it was observed that samples in conventional oven showed a uniform temperature, in contrast with those heated by microwave radiation. Such results are useful for designing hybrid systems for drying coffee beans.

RESUMEN: El presente artículo reporta los resultados de una investigación experimental, obtenidos en el secado de granos de café variedad Castilla, originarios de Santander, Colombia. Los experimentos fueron llevados a cabo a través de dos técnicas: radiación térmica y radiación electromagnética. Veinte experimentos fueron realizados, 10 en un horno microondas a $2.450 \mathrm{MHz}-1.080 \mathrm{~W}$, y 10 en un horno eléctrico convencional con temperatura controlada a $50 \pm 2{ }^{\circ} \mathrm{C}$. Las pruebas fueron hechas a muestras de grano con cascarilla, sin cascarilla y a la sola cascarilla. En cada experimento se determinó la relación de humedad adimensional del proceso de secado, y su coeficiente de difusión, de acuerdo con la segunda ley de Fick. Se encontró que el coeficiente de difusión de las muestras secadas en horno microondas fue veintidós veces mayor que el respectivo coeficiente de las muestras secadas en horno eléctrico. Las muestras secadas por radiación térmica mantuvieron una temperatura uniforme, en contraste con las muestras secadas por microondas. Los resultados son de gran utilidad para el posterior estudio de sistemas híbridos de secado de granos de café.

\section{Introduction}

The coffee bean handling in post-harvesting, requires appropriate drying process conditions, to obtain characteristics demanded by the market. Both, conventional drying with thermal radiation and with electromagnetic waves (radiofrequency and microwave) have received a great deal of attention. For the particular case of electromagnetic waves, in the radio frequency and

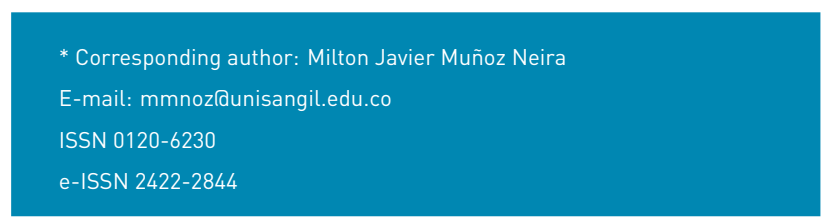

microwave range, it has experimented in various ways since the second half of the 20th century. An early study [1] outlines the possible uses of these for grain drying, seed treatment, pest control, food processing, and moisture content measurement. This work refers, for example, experiments for the drying of corn grains dating from 1967. A later work [2] proposes a strategy to reduce drying time in continuous flow dryers, for grains with high moisture content, performing a pre-heating stage by means of microwaves. Other researchers, [3-5], also presented a study for corn grains, but dedicated to calculating equilibrium moisture within a microwave drying system, and to the drying analysis in this system, for microwave operated continuously and intermittently. 
These investigators conclude that the intermittent operation of microwaves considerably reduces energy costs, at the expense of increased drying time, and recommends applications with a useful time of $5 / 15$ minutes at powers of $0.5 \mathrm{~W} / \mathrm{g}$, to obtain seeds of good quality.

A more recent work randomly selected, was oriented to investigate dry milling of previously dried grains in a domestic microwave oven [6]. Other work reports the study of a microwave vacuum drying system of granulated material [7], and another one analyzes the temperature variations in barley and canola grains with different moisture contents [8]. This last work details the influence of such grain in temperature uniformity when using microwave-based heating. It focuses on how the temperature rises within grains: higher temperatures are expected when exposing longer to microwaves, and lower ones are expected for cases with high initial moisture content.

A similar investigation [9] indagated the non-uniformity of the surface temperature of cereal grains and oilseeds dried by microwaves. For the author, this non-uniformity is the biggest drawback in this type of drying.

In recent years, there are also a number of works dedicated to the drying of grains with microwaves. One of them examined the effects on the microstructure and quality of dried potato slices, through a vacuum freeze dryer and a microwave freeze dryer, the latter being faster, more efficient and with similar effects on the product, with respect to the first [10]. A posterior research [11], examined the drying of corn grains in a fluidized bed assisted by microwaves, with an initial moisture content of $26 \%$ (dry-basis, db), for temperatures between $30^{\circ} \mathrm{C}$ and $60^{\circ} \mathrm{C}$ and powers between 180 and $900 \mathrm{~W}$. With the experiments thus obtained, an artificial neural network was trained to predict the drying time, achieving a prediction efficiency of $99 \%$. In a parallel area [12], a work developed a simulation for the analyses of the energy and exergy performance of a fluidized bed assisted by microwaves, for the drying of soybeans. The effects of the temperature of the air entering the system, the air speed, the power of the microwave and the thickness of the drying layer were simulated, achieving an $86 \%$ similarity with respect to the experimental data. A more contemporary study [13] in a microwave-assisted hot air drying system determined the drying kinetics for peanut kernels, in a controlled experiment at $20^{\circ} \mathrm{C}$ in the air temperature, and microwaves with powers of $850 \mathrm{~W}$ and $2,450 \mathrm{~W}$.

Ghosh et al. presented a study concerning to drying of coffee beans [14]. They explored the drying kinetics for a microwave system join to an assisted hot air system at $45^{\circ} \mathrm{C}$. The authors worked with power ranges between $500 \mathrm{~W}$ and $1,500 \mathrm{~W}$, and with three different transport speeds between $5 \mathrm{~mm} / \mathrm{s}$ and $15 \mathrm{~mm} / \mathrm{s}$. In an alternate area, another study [15] investigated and modeled a drying of canola seeds in a microwave-assisted convection dryer. The same author [16], made a similar subsequent work, this time on different oilseeds. From the investigation, it is concluded that by controlling the temperature of the air that reaches the grains, its cracking or bursting is avoided, as a result of the handling of a lower pressure differential in the microwave-assisted system. Finally, other interesting work [17] presents the analysis of energy and exergy, as well as the modeling of a drying system for rice fields, by means of microwaves, carried out on a continuous band of industrial type, recommending the handling of layers of drying of $18 \mathrm{~mm}$ and powers in the system of $90 \mathrm{~W}$.

The present work reports the results of the comparative analysis of the drying of coffee beans, variety Castilla originating in the south of the department of Santander, Colombia, made in an electromagnetic cavity and in a conventional electric oven. The moisture loss curves, as well as the calculation of the diffusion coefficients of the coffee beans, for drying tests with parchment, without parchment, and for the single parchment, are reported. The research is desirable for future works on the design of hybrid systems for drying coffee beans.

\section{Materials and methods}

Twenty experiments were performed, divided into two groups, ten for drying in a microwave cavity $12,450 \mathrm{MHz}$, $1,080 \mathrm{~W})$, and ten for drying in a conventional electric oven fed at $120 \mathrm{~V}$ and with variable power so that its temperature was controlled by $50 \pm 2^{\circ} \mathrm{C}$. In each group, four tests were made for grain samples with parchment, four for grain samples without parchment, and two for samples of single parchment. The mass of the samples to be dried was approximately $63.5 \mathrm{~g}$. The samples were prepared by hydrating them in distilled water for $48 \mathrm{~h}$. After this time, the fermented grains were washed again in distilled water and laid to rest for a variable time between $20 \mathrm{~min}$ and $30 \mathrm{~min}$. This follows the washing and fermentation sequence that is carried out with the grains in the farms, in the so-called "wet process".

The samples were arranged in a single layer of approximately $5.5 \mathrm{~mm}$ in thickness. When drying in an electric oven, the first three measurements of mass loss were taken every $20 \mathrm{~min}$, the next two every $30 \mathrm{~min}$, and the rest every hour. In the drying in the microwave cavity, shots of $15 \mathrm{~s}$ were made, after which the samples were taken out of the oven and weighed. The time between the extraction of the samples, their weight, and their 
registration, averaged $1.5 \mathrm{~min}$. The oven was operated with a turntable at an average speed of $3 \mathrm{rpm}$. In both cases, the mass was measured on an electronic scale with a maximum range of $200 \mathrm{~g}$ and a resolution of $0.01 \mathrm{~g}$.

Using a Fluke Tis50 thermographic camera, it was verified that the temperature of the electric oven was regulated at $50 \pm 2^{\circ} \mathrm{C}$, and the temperature of the samples was recorded after being radiated in the microwave oven. Likewise, with the help of the optical fiber system brand FISO with $0.025 \%$ accuracy, the curve of temperature variation in the samples was captured when they were radiated in the microwave cavity. For this, the microwave cavity had an optical fiber temperature measurement system implemented. The measurement was made by inserting a fiber optic temperature sensor (FISO FOT-L-SD-C1-F1-M2-R1-ST) into the microwave oven. The measurement capability of the sensor is $300^{\circ} \mathrm{C}$. The sensor was adhered to the surface of the grains and to the parchment. Once the electromagnetic radiation was activated, the capture of the temperature data was started, with a sampling frequency of $1 \mathrm{~s}$, by means of a universal data acquisition instrument FISO UMI4. Data were transmitted to a computer, via a serial interface. The acquisition time of the data was adjusted to the time of the radiation (15s).

For the determination of the diffusion coefficients in the drying processes, the second law of Fick was followed (Equation 1).

$$
\frac{d M}{d t}=\nabla \cdot(\mathfrak{D} \nabla M)
$$

where $\mathfrak{D}$ is the effective coefficient of diffusion. For a sphere, as described by [18], the solution of Equation 1, has the form of Equation 2.

$$
M R=\frac{M-M_{e}}{M_{o}-M_{e}}=\frac{6}{\pi^{2}} \sum_{n=1}^{\infty} \frac{1}{n^{2}} e^{-\mathfrak{D} \frac{n^{2} \pi^{2} t}{r^{2}}}
$$

which is a sum of decreasing exponentials, where $M R$ is the dimensionless moisture relation, $M$ the moisture of the grains under test at time $t, M o$ the initial moisture of the grains, and $M e$ the equilibrium moisture, all measured in dry-base. On the other hand, $r$ is the radius of the sphere in millimeters and $\mathfrak{D}$ the effective coefficient of diffusion, in square millimeters per minute for the samples dried in an electric oven and for the samples dried in a microwave oven.

The initial moisture of the grains was determined as the difference between the initial mass of these and the dry mass, which was determined by submitting samples of mass similar to that of the samples to be dried, at a temperature of $104^{\circ} \mathrm{C}$ for one hour. Dry masses were calculated at $30.13 \mathrm{~g}, 31.28 \mathrm{~g}$, and $21.01 \mathrm{~g}$, for samples with parchment, without parchment, and for only-parchment, respectively.

The amount of humidity of each sample was calculated following Equation 3 [19], and moisture on dry-basis according to Equation 4.

$$
\begin{gathered}
M_{t}=1-\frac{\left(m_{0}\right) *\left(1-M_{0}\right)}{m_{t}} \\
M=\frac{M_{t}}{1-M_{t}}
\end{gathered}
$$

with $M_{t}$ equal to the humidity of the samples at time $t, m_{0}$ the initial mass of the samples, $m_{t}$ the mass of the sample at time $t$, and $M_{0}$ the initial humidity of the sample. These equations are valid for the grain with and without parchment, as well as for just the parchment.

Several authors to determine the diffusion coefficient and the kinetics of grain drying, such as [20-22] have used Equation 2. Since the geometry of the grain does not correspond exactly to a sphere, and that, consequently, the solution to the Fick equation given in Equation 2 is not exact, it is appropriate to adopt a more general solution [23], according to Equation 5.

$$
M R=\frac{M-M_{e}}{M_{0}-M_{e}}=\sum_{i=1}^{\infty} A_{i} e^{-k_{i} * t}
$$

From Equation 5, the effective coefficient of diffusion $\mathfrak{D}$, can be calculated by dividing the first-factor $k_{i}=1$ by $\pi^{2}$ and then multiplying by $r^{2}$, where $r$ is the average radius of the grains, which for the experiments was estimated at approximately $5.5 \mathrm{~mm}$.

From the experimental data of loss of humidity, and for each of the tests carried out, the Nelder-Mead optimization algorithm was used, in order to determine the parameters $A_{i}$ and $k_{i}$ in Equation 5, as well as to estimate a value for $M e$, in a sum of two terms. For each model found, the calculation of the root mean square error (RMSE) was performed, and the coefficient of determination $\gamma^{2}$, (Equations 6 and 7), with $N$ equal to the size of the data set, $M$ equal to the experimental humidity in dry-basis, and $M *$ equal to the calculated humidity, also in dry-basis.

$$
\begin{gathered}
R M S E=\sqrt{\frac{\sum_{1}^{N}\left(M-M^{*}\right)^{2}}{N}} \\
\gamma^{2}=1-\frac{\sum_{1}^{N}\left(M-M^{*}\right)^{2}}{\sum_{1}^{N}(M-\bar{M})^{2}}
\end{gathered}
$$

The results of the drying experiments are described below. 


\section{Results and discussion}

\subsection{Drying experiments}

Figures 1 and 2 show the variation of dimensionless humidity ratio (MR). In the first case, the variation is given with respect to time. In the second one, variation is given in the form of boxplots (whisker charts). Figure 3 shows the drying rate with respect to time. Figures 1 and 3 were generated using the average values of all tests and for each class of experiment. Oppositely, Figure 2 was created using a projection of the average drying model found for each experiment. Intervals of 700 and 60 minutes were considered for the electric oven and for microwaves, respectively.

Figure 1 compares drying curves from the electric oven (left subplot), and from microwave (right subplot). In both cases, a decreasing exponential drying curve is evidenced. However, microwave-based drying allows faster processing. While it may take $17 \mathrm{~h}$ to reach a value below $12 \%(d b)$ with the conventional oven Igrains with parchment), doing so with microwaves only requires about $1 \mathrm{~h}$. It is worth mentioning that this time considers times between radiation $(1.5 \mathrm{~min})$, as well as the duration of each radiation. For the case of grains without parchment, average times of $10 \mathrm{~h}$ and $40 \mathrm{~min}$, are respectively required. Hence, microwave-drying is 17 and 15 times faster on grains with and without parchment, respectively. For both drying methods (thermal and using microwaves), the drying time of only-parchment is very similar to the drying time of grain without parchment, although, the former is smaller.

In consequence, the grain with parchment dried in an electric oven at $50^{\circ} \mathrm{C}$, enters in a pseudo-equilibrium zone after approximately 1000 minutes, with an MR below 0.1 . This pseudo equilibrium region is the sector in which the moisture loss curve begins its slow and asymptotic descent towards equilibrium moisture. Here, humidity changes are less than $4 \%$. The result is similar to that presented by [24], for a drying model of coffee beans with parchment, at a temperature close to $54^{\circ} \mathrm{C}$. On the other hand, the grains without parchment, dried in an electric oven at $50^{\circ} \mathrm{C}$, enter the pseudo-equilibrium zone after approximately 550 minutes. This result is comparable to that obtained by [25], in the drying of bare grains (without parchment), at $50^{\circ} \mathrm{C}$.

In the case of microwaves, humidity reaches the pseudo-equilibrium after 60 and 40 minutes, for grains with and without parchment, respectively. The time to reach the pseudo-equilibrium for the grains with parchment is comparable to that determined by [26], for continuous radiation of $1 \mathrm{KW}$ (with vacuum pump at
$-0.085 \mathrm{mPa}$, and lower than the obtained by [14] for the same radiation level. This last experiment was done, however, with grains moving on a conveyor belt at $5 \mathrm{~mm} / \mathrm{s}$.
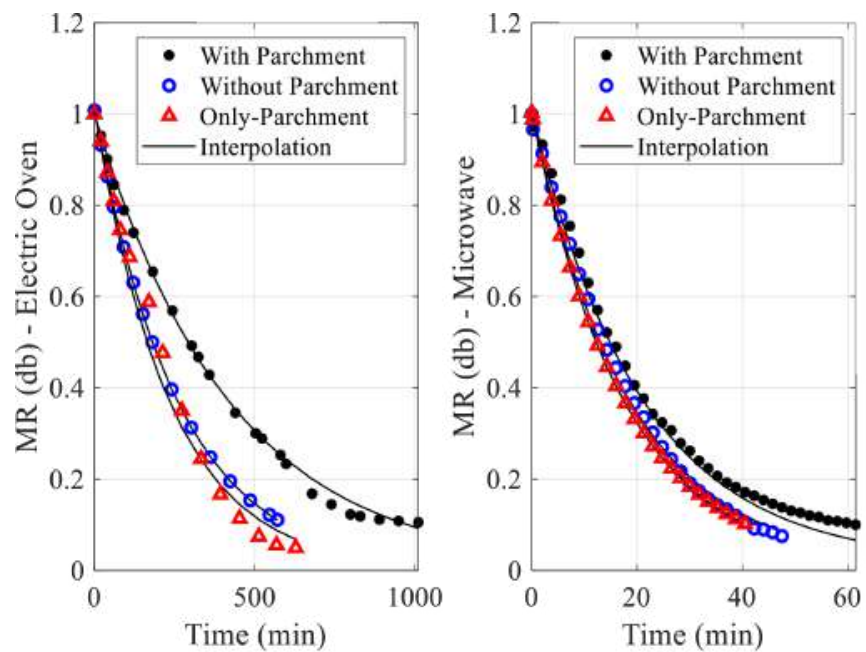

Figure 1 Dimensionless moisture ratio (MR) in electric and microwave oven
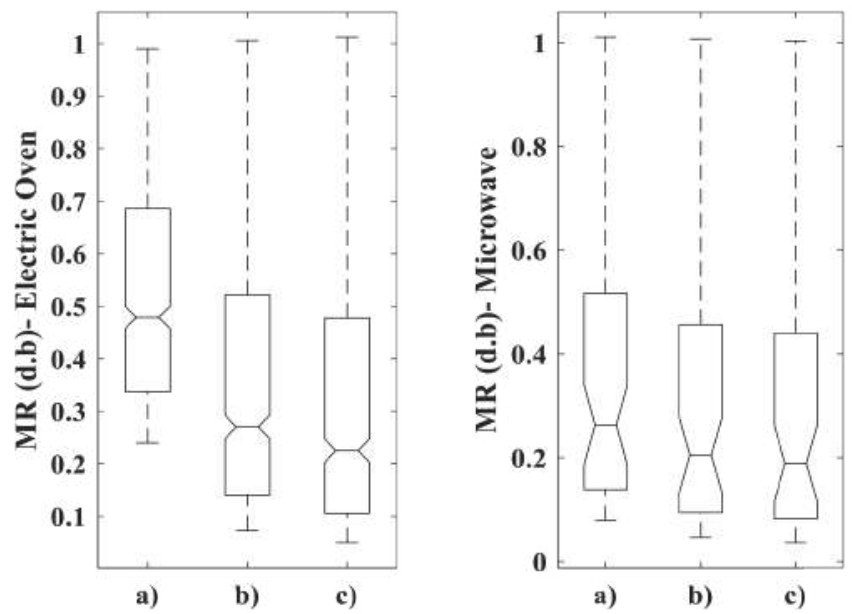

Figure 2 Whiskers charts from dimensionless moisture ratio data, a) With Parchment, b) Without Parchment, c) Only-Parchment

The presentation of MR variation in the form of whiskers charts (Figure 2) allows for a comparison of the different drying experiments. The greatest loss of moisture occurs in the first drying intervals. In effect, data between median and $75^{\text {th }}$ percentile is more spread out than those between the median and $25^{\text {th }}$ percentile. Also, it is evident that the MR kinetics is similar for all cases of microwave-based drying. In contrast, the MR kinetics when drying through thermal radiation is quite different when the grain contains the parchment than when it does not, or when only the parchment is considered. Such a 
behavior can be determined by evaluating the median of each experiment. For microwave drying, medians with and without parchment differ on average by $5 \%$, while the ones for thermal radiation differ by more than $10 \%$.

Drying rate curves manifest, equally, that MR loss decreases exponentially. Two regions can be identified. The first one is given by rapid deceleration, while the second one has the opposite behavior. The turning point is nearby to the time of the median MR: 320 and 330 minutes for grain with and without parchment, respectively, when using the electric oven. In the case of the microwave, such times were located at 30 and 28 minutes, respectively.
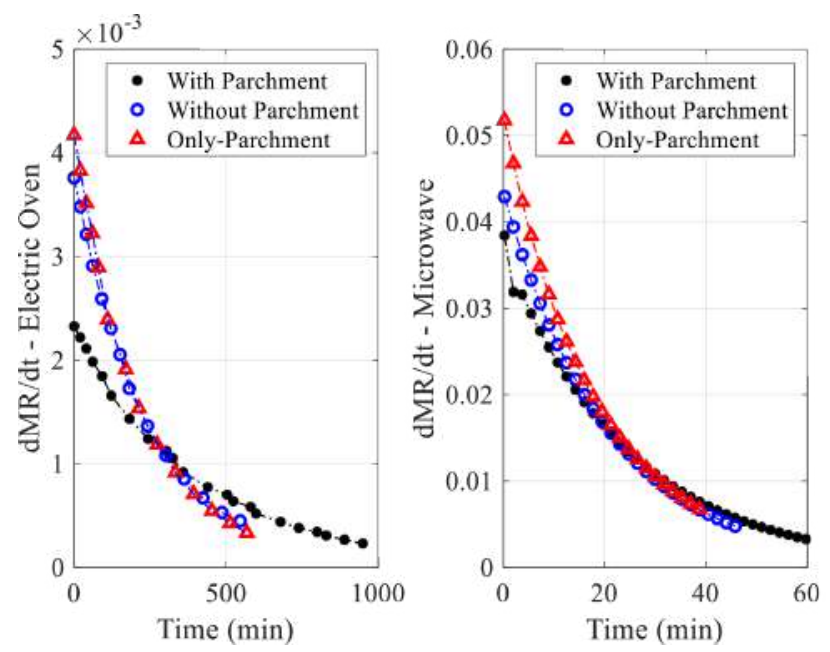

Figure 3 Drying Rate (dMR/dt) in electric and microwave oven

The evident advantage in time that the drying in the microwave cavity provides is affected by the lack of uniformity in the temperature of the grains (see Figure 4). which is highly uniform in drying by means of an electric oven (see Figure 5). While the temperature of the samples in the electric oven drying, is always close to $50^{\circ} \mathrm{C}$ (which was the control temperature set for the oven), the temperature of the samples dried in a microwave oven can vary from $30^{\circ} \mathrm{C}$ to $100^{\circ} \mathrm{C}$, or even $120^{\circ} \mathrm{C}$ for some grains.

The above circumstance was corroborated by measuring the surface temperature of a grain sample and of parchment. As aforementioned, we used high precision optical sensors. Figures 6 and 7 show that samples can exhibit temperatures of $80^{\circ} \mathrm{C}$ and $90^{\circ} \mathrm{C}$, for grains with and without parchment, respectively. This happens when the cavity is activated for the first and second radiation. In Figure 6, "first radiation" refers to the measurement of the surface temperature of the grains, in the microwave oven, during the first radiation of 15 seconds. In Figure 7 , "second radiation", refers to the measurement of the surface temperature of the grains, in the microwave oven, during the second radiation, also with a duration of 15 seconds. We allowed a time-lapse of one and a half minutes between radiations.

Drying experiments with a shorter radiation time (5 seconds) were carried out (see Figure 8), achieving temperatures in the samples close to $63^{\circ} \mathrm{C}$, but with final humidity percentages close to $30 \%$, a value that is high with respect to the final moisture value required for coffee grains (between $10 \%$ and $12 \%, \mathrm{db}$ ). As an additional experiment, we added a substrate of Silicon Carbide, SiC, at the base of samples. The effect was a drying curve with the same MR loss pattern, but with higher temperatures. Figures 8 and 9 summarize the data and compare them to the drying of grains with parchment (15-second radiation). The former was obtained by averaging real values of the four tests performed, for each type of experiment. As in the case of Figure 2, Figure 9 results from a projection of the average drying model found for each experiment. But in this case, it was done for an interval of 70 minutes.

\subsection{Diffusion coefficients}

The parameters of Equation 5, found by means of the Nelder-Mead optimization algorithm for each drying experiment carried out, as well as the calculation of the diffusion coefficients, are detailed in the following tables (Table 1-4).

Diffusion coefficients of microwave-based experiments were higher than those from the electric oven experiments. On average, the diffusion coefficient for grain with parchment was 22 times larger when using microwaves than when using thermal radiation. Similar behavior occurred for grain without parchment. On this occasion, the diffusion coefficient increased 15 times. This did visible that removing the parchment improves diffusion coefficients. The average coefficient increase was 1.12 and 1.7 for microwaves and electric oven, respectively.

On the other hand, the diffusion coefficient of the parchment was 1.1 and 1.14 times greater than the average diffusion coefficient of dried grains without the parchment, for microwaves and electric oven, respectively. Likewise, the coefficient of grains dried in the microwave cavity with radiations of 5 seconds, was $80 \%$ lower than the coefficient of grains dried with radiations of 15 seconds. Adding a substrate to the base of the dish on which the samples were dried increased diffusion coefficient by $2 \%$.

The second law of Fick (Equation 1) considers that the diffusion coefficient is independent of bean structure. But, coefficients of determination below 0.99 indicate that this is not true for all cases [27]. For the tests carried out, this is evident when drying grains without parchment in the electric oven and when doing so for just the parchment. 

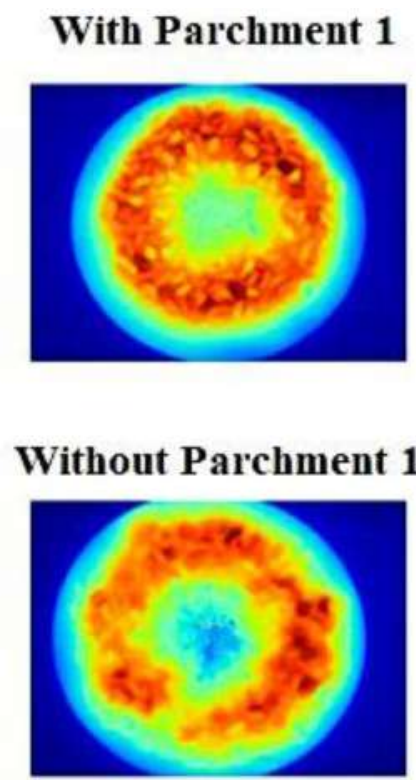
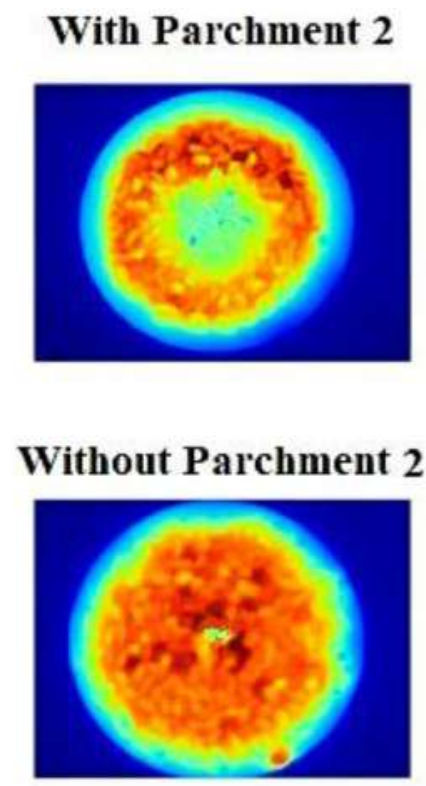

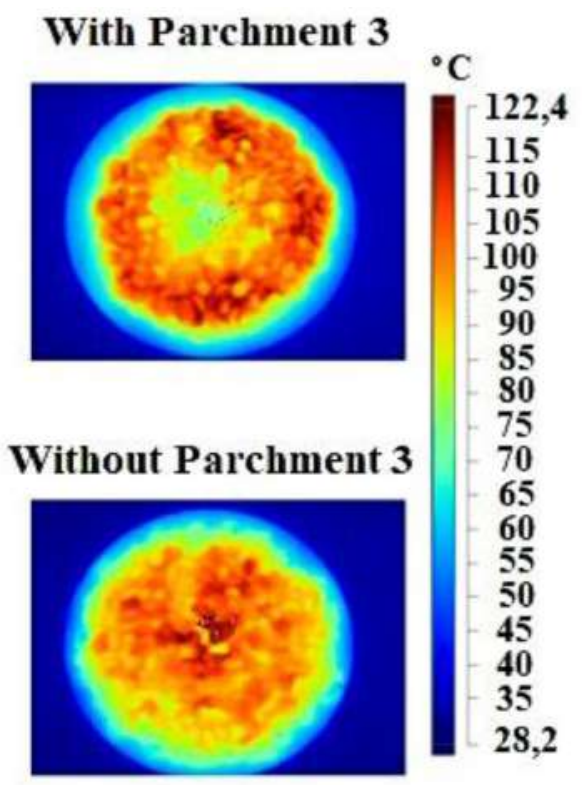

Figure 4 Thermographic photographs of coffee beans dried in a microwave oven for three radiations $\left({ }^{\circ} \mathrm{C}\right)$

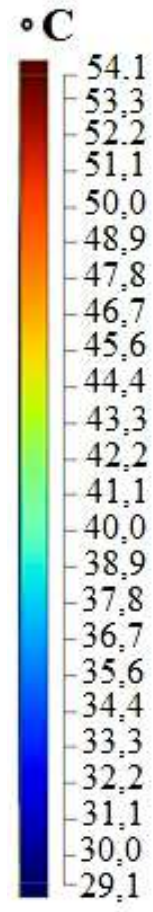

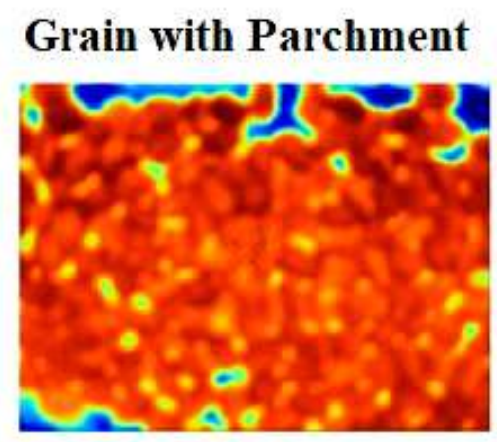

\section{Parchment}

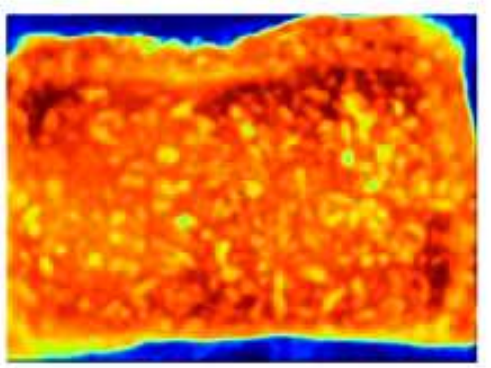

\section{Grain without Parchment}
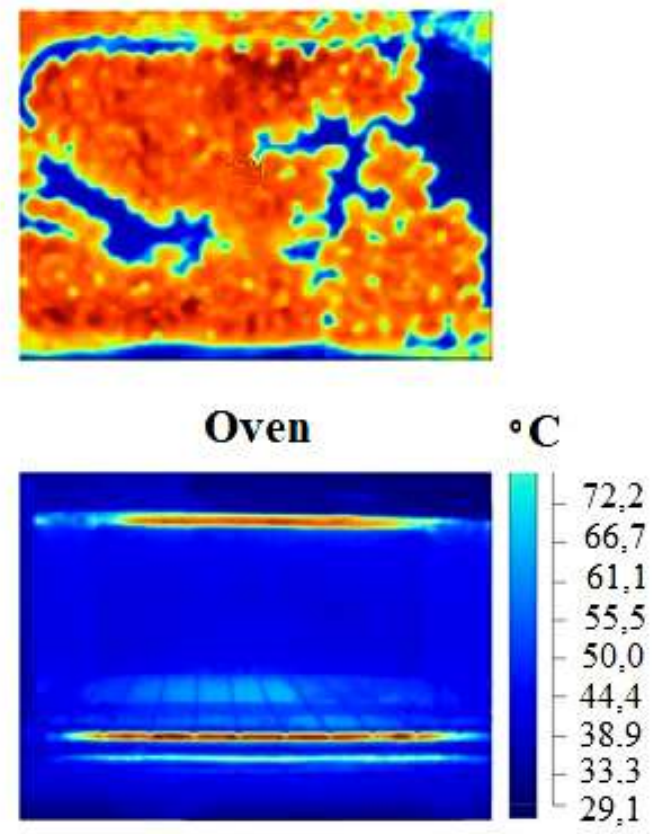

Figure 5 Thermographic photographs of coffee beans dried in an electric oven $\left({ }^{\circ} \mathrm{C}\right)$

\section{Conclusions}

Throughout this work, 20 drying tests were performed on coffee beans. Ten of them considered thermal radiation from an electric oven and the other ten used electromagnetic radiation within a microwave cavity. Samples included grains with parchment, without parchment and single parchment. Microwave-based drying was faster. Processing time reduced in a factor of 17 and 15, for samples of coffee with and without parchment, respectively. Likewise, diffusion coefficients of microwave-dried grains were 22 and 15 times higher than those dried in the electric oven. The temperature of grains dried by thermal radiation was uniform and close to the control temperature of the oven. However, the temperature of those dried with microwaves was 
Table 1 Experimental results for coffee beans dried with parchment

\begin{tabular}{|c|c|c|c|c|c|c|c|c|}
\hline \multicolumn{9}{|c|}{ Electric oven } \\
\hline TEST & $a_{1}$ & $\mathbf{k}_{1}$ & $a_{2}$ & $k_{2}$ & $\begin{array}{l}\mathfrak{D} \\
\mathrm{mm}^{2} / \mathrm{min}\end{array}$ & $\mathrm{Me}$ & RMSE & $\gamma^{2}$ \\
\hline 1 & 0.91450 & 0.0025 & 0.04552 & 0.00250 & 0.00766 & 0.052473 & 0.0212 & 0.9959 \\
\hline 2 & 0.97650 & 0.0017 & 0.03380 & 0.01000 & 0.00514 & 0.000100 & 0.0289 & 0.9920 \\
\hline 3 & 0.98720 & 0.0024 & 0.01360 & 0.00100 & 0.00736 & 0.002067 & 0.0156 & 0.9978 \\
\hline 4 & 0.97623 & 0.0023 & 0.02019 & 0.00336 & 0.00705 & 0.001680 & 0.0155 & 0.9977 \\
\hline \multicolumn{9}{|c|}{ Microwave cavity } \\
\hline TEST & $a_{1}$ & $k_{1}$ & $a_{2}$ & $\mathbf{k}_{2}$ & $\begin{array}{l}\mathfrak{D} \\
\mathrm{mm}^{2} / \mathrm{min}\end{array}$ & $\mathrm{Me}$ & RMSE & $\gamma^{2}$ \\
\hline 1 & 0.99 & 0.0472 & 0.027 & 0.0033 & 0.1447 & 0.042 & 0.0292 & 0.9909 \\
\hline 2 & 0.99 & 0.0479 & 0.019 & 0.0023 & 0.1468 & 0.080 & 0.0253 & 0.9921 \\
\hline 3 & 0.99 & 0.0486 & 0.019 & 0.0023 & 0.1490 & 0.090 & 0.0224 & 0.9938 \\
\hline 4 & 0.98 & 0.0472 & 0.027 & 0.0023 & 0.1447 & 0.042 & 0.0201 & 0.9953 \\
\hline
\end{tabular}

Table 2 Experimental results for coffee beans dried without parchment

\begin{tabular}{|c|c|c|c|c|c|c|c|c|}
\hline \multicolumn{9}{|c|}{ Electric oven } \\
\hline TEST & $a_{1}$ & $k_{1}$ & $a_{2}$ & $\mathbf{k}_{2}$ & $\begin{array}{l}\mathcal{D} \\
\mathrm{mm}^{2} / \mathrm{min}\end{array}$ & $\mathrm{Me}$ & RMSE & $\gamma^{2}$ \\
\hline 1 & 0.97 & 0.0038 & 0.05 & 0.004 & 0.01165 & 0.001 & 0.0463 & 0.9821 \\
\hline 2 & 0.98 & 0.0037 & 0.034 & 0.004 & 0.01134 & 0.006 & 0.0356 & 0.9886 \\
\hline 3 & 0.98 & 0.0039 & 0.028 & 0.003 & 0.01195 & 0.004 & 0.0312 & 0.9908 \\
\hline 4 & 1.00 & 0.0037 & 0.020 & 0.002 & 0.01134 & 0.002 & 0.0431 & 0.9851 \\
\hline \multicolumn{9}{|c|}{ Microwave cavity } \\
\hline TEST & $a_{1}$ & $\mathbf{k}_{1}$ & $a_{2}$ & $\mathbf{k}_{2}$ & $\begin{array}{l}\mathfrak{D} \\
\mathrm{mm}^{2} / \mathrm{min}\end{array}$ & $\mathrm{Me}$ & RMSE & $\gamma^{2}$ \\
\hline 1 & 0.96 & 0.0570 & 0.052 & 0.024 & 0.1747 & 0.001 & 0.0287 & 0.9911 \\
\hline 2 & 0.96 & 0.0579 & 0.052 & 0.024 & 0.1775 & 0.001 & 0.0297 & 0.9902 \\
\hline 3 & 0.95 & 0.0555 & 0.052 & 0.024 & 0.1701 & 0.001 & 0.0177 & 0.9965 \\
\hline 4 & 0.95 & 0.0565 & 0.052 & 0.024 & 0.1732 & 0.001 & 0.0164 & 0.9970 \\
\hline
\end{tabular}

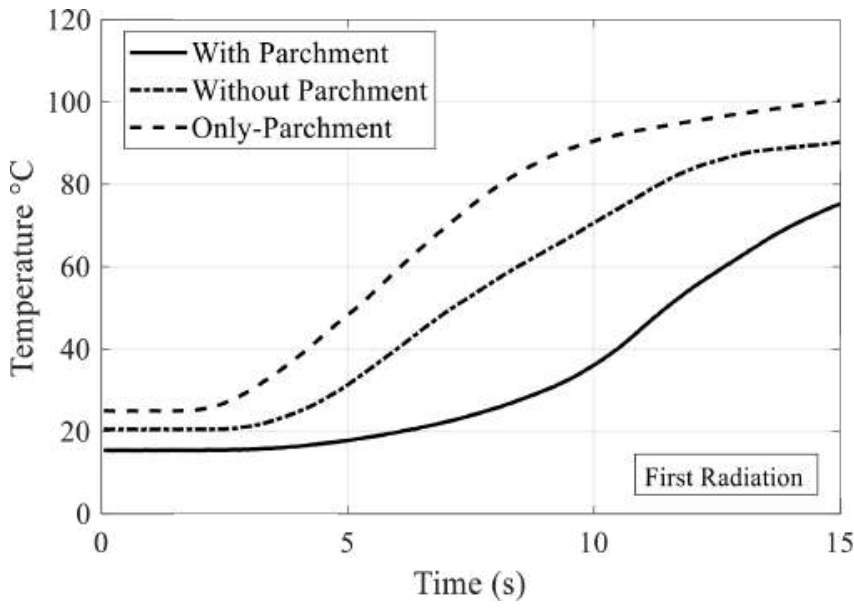

Figure $\mathbf{6}$ Increase of temperature in the surface of the coffee bean for samples dried in the microwave cavity, during the first radiation of $15 \mathrm{~s}$, measured with a fiber optic temperature sensor (brand: FISO)

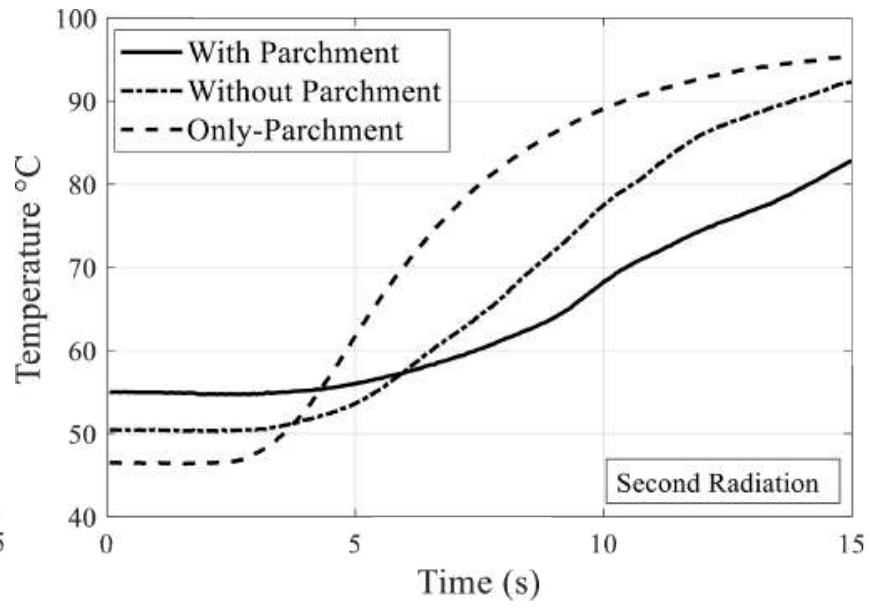

Figure 7 Increase of temperature in the surface of the coffee bean for samples dried in microwave cavity during the second radiation of $15 \mathrm{~s}$, measured with a fiber optic temperature sensor (brand: FISO) 
Table 3 Experimental results for dried of only-parchment

\begin{tabular}{|c|c|c|c|c|c|c|c|c|}
\hline \multicolumn{9}{|c|}{ Electric oven } \\
\hline TEST & $a_{1}$ & $\mathbf{k}_{1}$ & $a_{2}$ & $\mathbf{k}_{2}$ & $\begin{array}{l}\mathfrak{D} \\
\mathrm{mm}^{2} / \min \end{array}$ & Me & RMSE & $\gamma^{2}$ \\
\hline 1 & 0.965 & 0.0043 & 0.0513 & 0.0032 & 0.01318 & 0.002 & 0.0918 & 0.9828 \\
\hline 2 & 1.001 & 0.0043 & 0.0113 & 0.00432 & 0.01318 & 0.002 & 0.0843 & 0.9847 \\
\hline \multicolumn{9}{|c|}{ Microwave cavity } \\
\hline TEST & $a_{1}$ & $\mathbf{k}_{1}$ & $a_{2}$ & $\mathbf{k}_{2}$ & $\begin{array}{l}\mathfrak{D} \\
\mathrm{mm}^{2} / \mathrm{min}\end{array}$ & $\mathrm{Me}$ & RMSE & $\gamma^{2}$ \\
\hline 1 & 0.475 & 0.0600 & 0.530 & 0.0275 & 0.1839 & 0.003 & 0.044 & 0.9928 \\
\hline 2 & 0.801 & 0.0595 & 0.202 & 0.0471 & 0.1824 & 0.001 & 0.141 & 0.9503 \\
\hline
\end{tabular}

Table 4 Experimental results for coffee beans dried in the microwave with a substrate of SiC - radiation of 15s, and without substrate - radiation of $5 \mathrm{~s}$

\begin{tabular}{|c|c|c|c|c|c|c|c|c|}
\hline \multicolumn{9}{|c|}{ Microwave Oven - With Parchment and Substratum - Radiation each 15s } \\
\hline TEST & $a_{1}$ & $\mathbf{k}_{1}$ & $a_{2}$ & $\mathbf{k}_{2}$ & $\begin{array}{l}\mathfrak{D} \\
\mathrm{mm}^{2} / \mathrm{min}\end{array}$ & Me & RMSE & $\gamma^{2}$ \\
\hline 1 & 0.97 & 0.0485 & 0.027 & 0.0023 & 0.1487 & 0.0420 & 0.0121 & 0.9983 \\
\hline \multicolumn{9}{|c|}{ Microwave Oven - With Parchment - Radiation each 5 s } \\
\hline TEST & $a_{1}$ & $\mathbf{k}_{1}$ & $a_{2}$ & $\mathbf{k}_{2}$ & $\begin{array}{l}\mathfrak{D} \\
\mathrm{mm}^{2} / \mathrm{min}\end{array}$ & Me & RMSE & $\gamma^{2}$ \\
\hline 1 & 0.97 & 0.0097 & 0.030 & 0.0433 & 0.0297 & 0.0445 & 0.0228 & 0.9901 \\
\hline
\end{tabular}

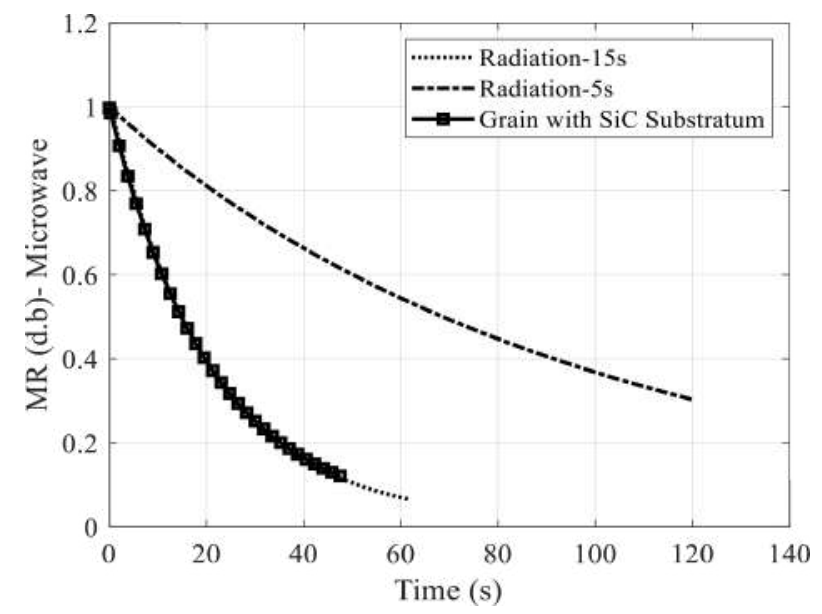

Figure 8 Comparison of drying curves with radiation of 15 seconds, 5 seconds, and drying with $\mathrm{SiC}$-substratum

not uniform and reached values beyond $100^{\circ} \mathrm{C}$. Based on the data, it can be inferred that a hybrid system for drying coffee beans seems like a feasible alternative. Such a system would use microwaves in short bursts (five seconds). This would be complemented with methods offering uniform drying temperature, such a solar collector. In doing so, the process could be optimized to deliver samples with moisture values below $12 \%(\mathrm{db})$.

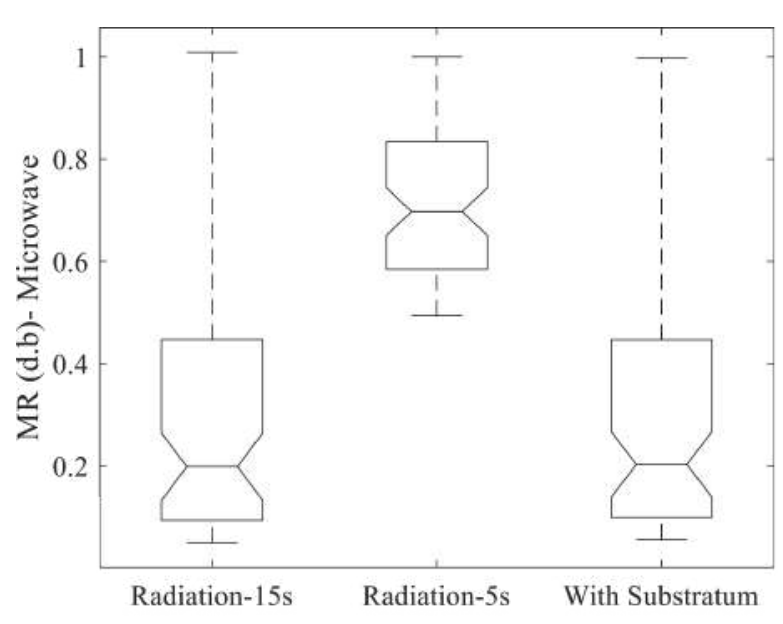

Figure 9 Whiskers charts for drying with radiation of 15 seconds, 5 seconds, and 15 seconds with SiC-substratum

\section{Acknowledgments}

The authors express their gratitude to the Universidad Industrial de Santander, to "Café Legendario Company" that provided the coffee samples, to COLCIENCIAS for the financial support to Milton Muñoz and Manuel Roa, and to Unisangil for research time given to Milton Muñoz. 


\section{References}

[1] S. 0. Nelson, "Potential agricultural applications for $\mathrm{rf}$ and microwave energy," Transactions of the ASAE, vol. 30, no. 3, 1987. [Online]. Available: https://doi.org/10.13031/2013.30480

[2] W. Radajewski, P. Jolly, and G. Y. Abawi, "Optimization of solar grain drying in a continuous flow dryer," Journal of Agricultural Engineering Research, vol. 38, no. 2, 1987. [Online]. Available: https://doi.org/10.1016/0021-8634(87)90125-9

[3] U. S. Shivhare, V. G. S. Raghavan, and R. G. Bosisio, "Microwave drying of corn I. equilibrium moisture content," Transactions of the $A S A E$, vol. 35, no. 3, May 1992. [Online]. Available: https: //doi.org/10.13031/2013.28683

[4] U. S. Shivhare and V. G. S. Raghavan and R. G. Bosisio, "Microwave drying of corn II. constant power, continuous operation," Transactions of the ASAE, vol. 35, no. 3, May 1992. [Online]. Available: https://doi.org/10.13031/2013.28684

[5] U. S. Shivhare and V. G. S. Raghavan and R. G. Bosisio, "Microwave drying of corn III. constant power, intermittent operation," Transactions of the ASAE, vol. 35, no. 3, May 1992. [Online]. Available: https://doi.org/10.13031/2013.28685

[6] V. Velu, A. Nagender, P. G.Prabhakara, and D. G.Rao, "Dry milling characteristics of microwave dried maize grains (Zea mays l.)," Journal of Food Engineering, vol. 74, no. 1, May 2006. [Online]. Available: https://doi.org/10.1016/j.jfoodeng.2005.02.014

[7] M. N. Berteli, E. Rodier, and A. Marsaioli, "Study of the microwave vacuum drying process for a granulated product," Brazilian Journal of Chemical Engineering, vol. 26, no. 2, April 2009. [Online]. Available: http://dx.doi.org/10.1590/S0104-66322009000200009

[8] A. Manickavasagan, D. S. Jayas, and N. D. G. White, "Non-uniformity of surface temperatures of grain after microwave treatment in an industrial microwave dryer," Drying Technology, vol. 24, no. 12, December 2006. [Online]. Available: https://doi.org/10.1080/ 07373930601030796

[9] R. Vadivambal, D. S. Jayas, C. Vellaichamy, and N. D. G. White, "Preliminary study of surface temperature distribution during microwave heating of cereals and oilseed," Canadian Biosystems Engineering/Le Genie des biosystems au Canada, vol. 51, no. 3, pp. 3-45, Jan. 2009.

[10] R. Wang, M. Zhang, and A. S. Mujumdar, "Effects of vacuum and microwave freeze drying on microstructure and quality of potato slices," Journal of Food Engineering, vol. 101, no. 2, November 2006. [Online]. Available: https://doi.org/10.1016/j.jfoodeng.2010.05.021

[11] L. Momenzadeh, A. Zomorodian, and D. Mowla, "Experimental and theoretical investigation of shelled corn drying in a microwave-assisted fluidized bed dryer using artificial neural network," Food and bioproducts processing, vol. 89, no. 1, January 2011. [Online]. Available: https://doi.org/10.1016/j.fbp.2010.03.007

[12] M. Ranjbaran and D. Zare, "Simulation of energetic- and exergetic performance of microwave-assisted fluidized bed drying of soybeans," Energy, vol. 59, September 15 2013. [Online]. Available: https://doi.org/10.1016/j.energy.2013.06.057

[13] (2013) Cinética de secado de maní alto oleico en microondas combinado con aire. Asociación Argentina de Ingenieros Químicos. Accessed Aug. 18, 2018. [Online]. Available: https://bit.ly/2NrttU2
[14] P. Ghosh and N. Venkatachalapathy, "Thin layer drying of hot-air assisted microwave drying of parchment coffee," International journal of latest trends in engineering and technology, vol. 4, no. 4, pp. 121-133, Nov. 2014.

[15] M. Hemis, R. Choudhary, Y. Gariépy, and V. G. S.Raghavan, "Experiments and modelling of the microwave assisted convective drying of canola seeds," Biosystems Engineering, vol. 139, November 2015. [Online]. Available: https://doi.org/10.1016/j.biosystemseng. 2015.08.010

[16] M. Hemis, R. Choudhary, N. Becerra, P. Kohli, and V. Raghavan, "Modelling of microwave assisted hot-air drying and microstructural study of oilseeds," International Journal of Agricultural and Biological Engineering, vol. 9, no. 6, November 2016. [Online]. Available: https://doi.org/10.3965/j.ijabe.20160906.2442

[17] H. Jafari, D. Kalantari, and M. Azadbakht, “Semi-industrial continuous band microwave dryer for energy and exergy analyses, mathematical modeling of paddy drying and it's qualitative study," Energy, vol. 138, November 2017. [Online]. Available: https://doi.org/10.1016/j.energy.2017.07.111

[18] J. Crank, The mathematics of diffusion, 2nd ed. Great Britain: Oxford University Press, 1975.

[19] J. M. Jurado, E. C. Montoya, C. E. Oliveros, and J. Alzate, "Método para medir el contenido de humedad del café pergamino en el secado solar del café," Cenicafé, vol. 60, no. 2, pp. 135-147, 2009.

[20] A. D. Sharma, O. R. Kunze, and H. D. Tolley, "Rough rice drying as a two-compartment model," Transactions of the ASAE, vol. 25, no. 1 , 1982. [Online]. Available: https://doi.org/10.13031/2013.33508

[21] N. Varadharaju, C. Karunanidhi, and R. Kailappan, "Coffee cherry drying: a two-layer model," Drying Technology, vol. 19, no. 3-4, 2001. [Online]. Available: https://doi.org/10.1081/DRT-100103947

[22] P. C. Corrêa, G. H. Horta, A. P. Lelis, F. Mendes, and A. L. Duarte, "Thermodynamic properties of drying process and water absorption of rice grains," CyTA-Journal of Food, vol. 15, no. 2, 2017. [Online]. Available: https://doi.org/10.1080/19476337.2016.1238012

[23] M. J. Muñoz, R. Correa, and M. F. Roa, "Thermal analysis of coffee hulls and their effect on the drying process in conventional ovens," Indian Journal of Science and Technology, vol. 11, no. 36, October 2018. [Online]. Available: https://doi.org/10.17485/ijst/2018/v11i36/ 131682

[24] C. Zuluaga and L. Gómez, "Dynamic modeling of coffee beans dryer," in $2^{\text {nd }}$ Colombian Conference on Automatic Control (CCAC), Manizales, Colombia, 2015.

[25] M. M. Patiño, E. L. Pencue, and R. Vargas, “Determinación del contenido de humedad en granos de café pergamino seco utilizando speckle dinámico," Biotecnología en el Sector Agropecuario y Agroindustrial, vol. 14, no. 2, December 2016. [Online]. Available: https://doi.org/10.18684/BSAA(14)84-91

[26] W. Dong and et al, "Effect of microwave vac uum drying on the drying characteristics, color, microstructure, and antioxidant activity of green coffee beans," Molecules, vol. 23, no. 5, May 2018. [Online]. Available: https://doi.org/10.3390/molecules23051146

[27] A. Ramirez, "Internal structure and water transport in endosperm and parchment of coffee bean," Ph.D. dissertation, Dept. Mécanique des matériaux, Univ Montpellier II - Sciences et Techniques, Languedoc, France, 2011. 